\title{
SSynthesis
}

International Scientific Conference of IT and Business-Related Research

\section{PERSPEKTIVE MOBILNOG BANKARSTVA}

\section{MOBILE BANKING PERSPECTIVES}

\author{
Tamara Uroš \\ Beogradska poslovna škola, Visoka škola strukovnih studija, Beograd
}

\begin{abstract}
Apstrakt:
U uslovima globalizacije, tehnološkog napretka i porasta konkurencije banke su prisiljene da ponude nove servise kako bi zadržale postojeće i privukle nove klijente. Razvoj Interneta i mobilnih tehnologija, kao i fleksibilnost i pogodnost korišćenja mobilnih uređaja, uslovili su razvoj mobilnog bankarstva. Intenziviranje globalizacije kao posledicu ima veću mobilnost, što je uslovilo veću potrebu za mobilnim servisima koji se mogu realizovati u bilo koje vreme na bilo kom mestu (anytime, anywhere). Razvoj mobilnih komunikacionih tehnologija i eksplozivan rast broja korisnika mobilnih telefona ohrabrio je mnoge kompanije da razvijaju i lansiraju nove e-bankarske aplikacije i usluge poznate pod nazivom mobilno bankarstvo. U radu su opisani razlozi koji utiču na prihvatanje mobilnog bankarstva i mobilnog plaćanja, a objašnjene su i osnovne prepreke za njihovo prihvatanje - strah zbog nedovoljne bezbednosti i otpor velikog dela stanovništva prema novim tehnologijama.
\end{abstract}

\section{Ključne reči:}

mobilno plaćanje, mobilno bankarstvo, pametni telefoni, internet.

\section{UVOD}

Tehnološki napredak u oblasti telekomunikacija i informacionih tehnologija poslednjih nekoliko godina uticao je na razvoj bankarske industrije, pre svega na način isporuke finansijskih usluga. Banke nastoje da u skladu sa tehnološkim napretkom usvoje nove strategije kako bi zadovoljile potrebe svojih klijenata i ponudile im bolje proizvode i usluge istovremeno smanjujući operativne troškove.

Mobilno bankarstvo podrazumeva korišćenje mobilnih uređaja za pružanje bankarskih servisa kao što su: uvid u stanje na računu, pregled prethodno izvršenih transakcija, transfer fondova između računa, upozorenja o promeni stanja na računu, davanje naloga za plaćanje, trgovina akcijama, informacije o kamatnim stopama, deviznim kursevima i sl. Uređaji koji se koriste za mobilni pristup Internetu uključuju: notebook računare, PDA (Personal Digital Assistant) računare, tablet računare, mobilne telefone, pametne telefone (smartphone). Osnovna karakteristika ovih uređaja je da su prenosivi i raspoloživi u bilo koje vreme na bilo kom mestu. Mobilni servisi su dodali element mobilnosti konvencionalnim elektronskim bankarskim servisima koji se mogu realizovati preko fiksnih mreža.

Mobilna trgovina u poslednjoj dekadi zabeležila je neverovatan come-back, nakon kolapsa dot.com kompanija početkom ovog milenijuma, koji je uticao ne samo na elektronsku trgo-

\section{Abstract:}

In the context of globalization, technological advances and growing competition, the banks are forced to offer new services in order to maintain the existing and attract new customers. The development of the Internet and mobile technologies, as well as the flexibility and convenience of use of mobile phones, brought about the development of mobile banking. One of the consequences of the increasing globalization is greater mobility, which in turn causes greater demand for mobile services that can be used anytime and anywhere. The development of mobile communication technologies and explosive growth in the number of mobile phone users has triggered many companies to develop and launch new e-banking applications and services, known as mobile banking. The paper elaborates on the reasons for adopting mobile banking and mobile payment, and the basic obstacles to their acceptance, including the fear of insufficient security and resistance to new technologies targeting large segments of population.

\section{Key words:}

mobile payment, mobile banking, smart phones, the Internet.

vinu već i na mobilnu trgovinu, koja je počela da se razvija u to vreme. Pored nedostatka potražnje za mobilnim servisima, postojao je i problem tehnološke slabosti mobilnih uređaja, sporog prenosa podataka i nerazvijenih tehnoloških standarda. Ovi faktori su imali negativan uticaj na prihvaćenost mobilnih servisa. Međutim, od tada su se promenili mnogi uslovi u okruženju. Tehnološke inovacije su uklonile mnoge barijere. Glavni faktori za komercijalni uspeh mobilne trgovine su brzina, bezbednost i user-friendly korisnički interfejs mobilnih telekomunikacionih tehnologija (Uroš, 2014).

\section{KORIŠĆENJE MOBILNOG BANKARSTVA}

Sa porastom broja korisnika pametnih telefona koji imaju mogućnost pristupa internetu banke se sve više opredeljuju za isporuku bankarskih servisa preko mobilnih uređaja. Klijenti koji žele da obavljaju mobilne bankarske servise mogu da se prijave za ovu uslugu i sa veb-sajta banke preuzmu mobilnu bankarsku aplikaciju na svoj mobilni telefon. Od momenta kada je instaliraju u mogućnosti su da koriste mobilne bankarske servise po sopstvenoj želji, u bilo koje vreme, sa bilo kog mesta. Pri tom je ova usluga besplatna i zaračunava se kao cena bilo koje uobičajene komunikacije od strane mobilnog operatera. Porast broja mobilnih pretplatnika i jaka konkurencija između mobilnih operatera uticali su na konstantno poboljšanje kvali- 
teta usluga kao i na smanjenje cena. Ovo je motivisalo banke da ponude svoje usluge preko mobilnih telefona. Mobilni uređaji sve češće se koriste ne samo za obavljanje mobilnog bankarstva, već i mobilnog plaćanja i mobilne trgovine.

Glavni faktori koji su uticali na značajan porast korišćenja mobilnog bankarstva uključuju:

- Porast rasprostranjenosti pametnih telefona koji su omogućili korisnicima jednostavnu i spontanu interakciju sa brendovima preko interneta.

- Rast broja korisnika koji prihvataju nove tehnologije i relativno visok nivo poverenja u mobilne mreže i tehnologije koje banke koriste.

- Recesija je uslovila da potrošači postanu oprezniji u trošenju novca tako da se povećava broj onih koji koriste mobilne telefone za praćenje salda na njihovim računima i za budžetiranje, u cilju efikasnijeg upravljanja sopstvenim fondovima.

- Banke aktivno promovišu prednosti koje pruža mobilno bankarstvo. Mobilno bankarstvo se promoviše kao značajno poboljšanje u pogledu usluga koje klijenti dobijaju.

Istraživanja pokazuju da se među korisnicima mobilnog bankarstva većina opredeljuje za ovu uslugu zbog pogodnosti, tj. zbog toga što ne moraju da odlaze na šalter banke ili da koriste usluge pozivnog centra (55\%), što mogu jednostavno da provere da li imaju dovoljno sredstava na računu za plaćanje određenog iznosa (48\%), zbog uštede vremena (43\%), dok $22 \%$ smatra da im je to jednostavnije nego korišćenje kompjutera (Kam \& Riquelme, 2007).

Podaci pokazuju da broj korisnika mobilnog bankarstva raste eksponencijalno i da ova forma bankarstva postaje prihvaćena uprkos početnim strahovima vezanim za bezbednost. Milioni korisnika već su instalirali mobilne bankarske aplikacije na svoje telefone pomoću kojih obavljaju finansijske transakcije, što ukazuje na činjenicu da su ovi strahovi uglavnom prevaziđeni.

Rezultati istraživanja nedvosmisleno su pokazali da je mobilno bankarstvo doživelo iznenađujući povratak. Iako su mnogi eksperti verovali da je mobilno bankarstvo mrtvo nakon sloma dot.com kompanija, banke su ipak bile primorane da uvode mobilne servise. Razlozi ovog vaskrsnuća leže u neverovatnom razvoju telekomunikacionog sektora, sve široj prisutnosti mobilnih telefona i procesu globalizacije i integracije svetske ekonomije koji prisiljava poslovne ljude da se kreću unutar i van nacionalnih granica i obavljaju svoje bankarske poslove dok su u pokretu.

Pored toga što ubrzano raste broj korisnika mobilnog bankarstva, ovi korisnici su veoma zadovoljni uslugom i spremni su da preporuče drugim klijentima ovaj vid bankarstva. To se odrazilo na broj ljudi koji su prihvatili usluge mobilnog bankarstva kao rezultat preporuke od strane prijatelja i porodice $(25 \%$ korisnika je započelo korišćenje mobilnog bankarstva zbog toga što im je to neko preporučio) (Anderson et al., 2012).

Ljudi koji koriste mobilne telefone za obavljanje bankarskih transakcija uglavnom smatraju da je brzina bitan aspekt usluge i više su zainteresovani za tehnologije koje im puržaju mogućnost da uštede vreme (84\% korisnika mobilnog bankarstva veruju da im ovi servisi to omogućavaju). Ipak većina korisnika češće koristi personalni računar sa pristupom internetu da bi proverili stanje na svom računu, dok mobilni telefon u tu svrhu koriste samo povremeno, odnosno internet koriste kao primarni, a mobilni telefon kao komplementarni kanal (Anderson et al., 2012)

Odbor guvernera federalnog sistema rezervi prethodnih godina objavljivao je istraživanja vezana za prihvatanje mobilnog bankarstva i plaćanja u SAD-u. Ova istraživanja pokazuju da je 2012. godine $87 \%$ odraslih koristilo mobilne telefone, od kojih se $52 \%$ odnosilo na pametne telefone sa pristupom internetu
(Board of Governors of the Federal Reserve System, 2013). Rasprostranjenost mobilnih telefona menja način na koji korisnici pristupaju finansijskim uslugama. Istraživanje iz 2011. godine, na primer, pokazuje da je $22 \%$ korisnika mobilnih telefona i 43\% korisnika pametnih telefona koji imaju otvorene račune u bankama izjavilo da koristi usluge mobilnog bankarstva. Kasnija istraživanja pokazuju da je ovaj procenat svake godine bio sve veći, da bi 2014. godine dostigao 39\% korisnika mobilnih telefona i $52 \%$ korisnika pametnih telefona, dok $10 \%$ onih koji ne koriste ove usluge razmišlja o tome da će u narednih godinu dana početi sa njihovim korišćenjem (Board of Governors of the Federal Reserve System, 2015).

Najčešće korišćena usluga mobilnog bankarstva odnosi se na proveru stanja na računu i pregled nedavno izvršenih transakcija (94\% korisnika mobilnog bankarstva). Sledeća najčešće korišćena usluga odnosi se na transfer novca sa jednog korisnikovog računa na drugi i nju koristi $61 \%$ korisnika mobilnog bankarstva, a 57\% korisnika prima obaveštenja i upozorenja putem SMS-a ili imejla od strane njihove banke. Mobilni telefoni takođe menjaju način na koji korisnici obavljaju plaćanja: 22\% korisnika mobilnih telefona, odnosno $28 \%$ korisnika pametnih telefona obavljalo je mobilno plaćanje u toku 2014. godine (Board of Governors of the Federal Reserve System, 2015).

Glavna prepreka za šire prihvatanje mobilnih finansijskih servisa je sa jedne strane briga vezana za bezbednost, a sa druge strane percepcija o njihovoj ograničenoj korisnosti. Primarni razlog zbog kog korisnici mobilnih telefona ne prihvataju mobilne bankarske servise leži u tome što većina korisnika (54\%) smatra da svoje bankarske potrebe može da ostvari bez korišćenja mobilnog bankarstva. U pogledu mobilnog plaćanja 38\% korisnika ima strahove vezane za sigurnost, dok više od trećine korisnika mobilnih telefona jednostavno ne vidi korist od mobilnog plaćanja i smatraju da je to jednostavnije obaviti pomoću drugih metoda plaćanja (Board of Governors of the Federal Reserve System, 2014).

Potencijalna šteta od ignorisanja mobilnog bankarstva ne uključuje samo gubitak prihoda, već i mogućnost da klijenti pređu u drugu banku koja nudi ove servise. Banke pri ponudi mobilnih servisa treba da imaju u vidu koja je njihova ciljna grupa. Greška iz prethodnog perioda je bila u tome da se naglasak stavljao isključivo na grupu koja se može nazvati „tehnološki fanovi”. Međutim, članovi ove grupe imaju različite finansijske mogućnosti i ne mogu se smatrati atraktivnim za banku samo po tome što su tehnološki obrazovani. Taj njihov afinitet ka tehnologiji, iako je neophodan preduslov za korišćenje ovih servisa, nije sam po sebi dovoljan da bi ih posmatrali kao ciljnu grupu za mobilno bankarstvo.

Sledeća barijera je rizik koji sa sobom nosi inovacija. Online transakcije povećavaju bezbednosni rizik, kao i strahove u pogledu privatnosti kod korisnika. Neki korisnici se jednostavno plaše da će pogrešiti prilikom obavljanja bankarskih poslova preko računara ili mobilnog telefona, dok neki strahuju da će se veza prekinuti usred transakcije. Studije pokazuju da je pored teškoće korišćenja novih tehnologija, ovo sledeća najveća barijera za prihvatanje elektronskog bankarstva uopšte, a posebno mobilnog bankarstva.

Takođe, postoje i psihološke barijere, koje se odnose na promenu dnevnih rutina koje mogu izazvati inovacije. Barijere za korišćenje Internet bankarstva i mobilnog bankarstva postoje među korisnicima koji više vole direktan kontakt sa službenikom banke. Dakle, nemaju svi korisnici potrebu za novim, komplementarnim kanalima, već radije koriste tradicionalne kanale. Pored toga, neki korisnici smatraju da je tehnologija suviše teška za korišćenje i automatski stvaraju negativnu sliku o servisima koji su vezani za nove tehnologije. 
Istraživanje pokazuje da korišćenje pametnih telefona utiče na promenu načina kupovine: $47 \%$ korisnika pametnih telefona koristi svoje telefone za poređenje cena u različitim trgovinama i dobijanje informacija o proizvodima, što utiče na donošenje njihove odluke o tome koji proizvod i od kog trgovca će naručiti. U zavisnosti od ovih informacija $70 \%$ korisnika menja svoje navike u pogledu naručivanja. Preko 60\% korisnika mobilnog bankarstva proverava stanje na svom računu pre većih kupovina, a kao rezultat ove provere polovina njih odustaje od naručivanja. Približno 30\% korisnika mobilnih telefona je zainteresovano za primanje obaveštenja o popustima i ponudama baziranim na njihovoj lokaciji (Board of Governors of the Federal Reserve System, 2015).

Istraživanje, takođe, pokazuje da među onima koji ne koriste mobilno bankarstvo glavni način za interakciju sa finansijskom institucijom ostaje lični kontakt u filijali što preferira $85 \%$ ovih korisnika. Sledeći način pristupa bankarskim servisima odnosi se na internet bankarstvo (74\%) i korišćenje ATM uređaja (75\%), dok telefonsko bankarstvo koristi 34\% korisnika.

Korišćenje mobilnog bankarstva značajno je veće kod vlasnika pametnih telefona što ukazuje na to da će sa porastom učešća ovih telefona rasti i prihvatanje mobilnog bankarstva. Više od trećine korisnika izjasnilo se da je kupovina pametnih telefona bila glavni razlog za početek korišćenja mobilnog bankarstva (Lin, 2011).

Na prihvatanje servisa mobilnog bankarstva utiču demografske karakteristike korisnika, godine, obrazovanje, profesija i prihodi, dok između polova nema bitnih razlika. Starije i slabije obrazovane osobe teže prihvataju ove servise, dok mlađi, obrazovaniji, kao i oni koji rade na rukovodećim poslovima i imaju veće prihode od prosečnih, nisu toliko zabrinuti za rizike i promene njihovih dnevnih rutina, koje sa sobom nose mobilni servisi (Koenig-Lewis et al., 2010).

Korišćenje mobilnog bankarstva je u visokoj korelaciji sa godinama starosti ispitanika. Istraživanje iz 2011. godine pokazuje da je 39\% korisnika mobilnog bankarstva starosti između 18 i 29 godina, 34\% korisnika u starosnoj grupi od 30 do 44 godina, $19 \%$ korisnika je između 45 i 59 godina, a samo $8 \%$ korisnika ima preko 60 godina (Park et al., 2011).

Istraživanja pokazuju da kompatibilnost, odnosno stepen konzistentnosti novih usluga sa postojećim vrednostima, navikama i prethodnim iskustvima, ima pozitivan efekat na prihvatanje mobilnog bankarstva. Kompatibilnost podrazumeva prilagođenost životnom stilu korisnika i može pozitivno da utiče na bržu stopu prihvatanja. S obzirom na to da kompatibilnost ima značajnu korelaciju sa prihvatanjem i korišćenjem računara, može se očekivati slična veza između ovog parametra i prihvatanja u kontekstu mobilnog bankarstva.

Pozitivan efekat na prihvatanje mobilnog bankarstva ima i vidljivost ovih inovacija i korist koju one pružaju. U kontekstu mobilnog bankarstva pod tim se podrazumeva mogućnost pristupa bankarskim servisima u bilo koje vreme, sa bilo kog mesta, bez bilo kakvog zastoja i čekanja, kao i mogućnost trenutnog sagledavanja efekata mobilnih bankarskih transakcija.

Takođe, pozitivan efekat na prihvatanje može imati i mogućnost eksperimentisanja sa novim tehnologijama pre njihovog prihvatanja. Veća je verovatnoća prihvatanja mobilnog bankarstva ukoliko je potencijalnim korisnicima omogućeno da eksperimentišu sa inovacijama. Ukoliko se korisnicima pruži šansa da isprobaju inovacije to će umanjiti njihove strahove i voditi bržem prihvatanju. Banke koje obezbeđuju podršku i demonstriraju korišćenje mobilnog bankarstva u probnom periodu motivisaće potencijalne korisnike da brže prihvate usluge mobilnog bankarstva.
Složenost korišćenja mobilnog bankarstva ima negativan efekat na prihvatanje istog. Ona se može definisati kao stepen složenosti razumevanja i korišćenja novih mobilnih tehnologija. Postoji velik broj empirijskih istraživanja koja ukazuju na to da je glavna barijera za prihvatanje mobilnog bankarstva upravo složenost njegovog korišćenja.

Pored toga, i očekivani rizik može imati negativan efekat na prihvatanje mobilnog bankarstva. Rizik se odnosi na brigu vezanu za očuvanje privatnosti i strahove u pogledu bezbednosti. Potencijalni bezbednosni rizik odnosi se na otkrivanje PIN kodova i pristup bankarskim računima posredstvom ukradenih PIN kodova. Takođe, neki korisnici imaju strah od krađe njihovih mobilnih uređaja i podataka koji su uskladišteni na njima.

Mobilno plaćanje je i dalje relativno slabo prihvaćeno. Samo $15 \%$ korisnika mobilnih telefona, odnosno $24 \%$ korisnika pametnih telefona koristilo je mobilno plaćanje 2012. godine, što je neznatan porast od 3\% u odnosu na 2011. godinu (Board of Governors of the Federal Reserve System, 2013). Istraživanje iz 2014. godine pokazuju da je procenat mobilnog plaćanja povećan na $22 \%$ među korisnicima mobilnih telefona, odnosno na $28 \%$ među korisnicima pametnih telefona, što ukazuje na činjenicu da prihvatanje pametnih telefona doprinosi porastu korišćenja mobilnog plaćanja (Board of Governors of the Federal Reserve System, 2015). Učešće pametnih telefona u ukupnom broju mobilnih telefona značajno je poraslo i u decembru 2014. godine iznosi 71\% u odnosu na $61 \%$ u 2013. godini, 52\% u 2012. godini i 44\% u 2011. godini.

Među onima koji ne koriste mobilno plaćanje većina ispitanika (75\%) ne vidi nikakvu korist od ovog vida plaćanja i smatraju da je jednostavnije korišćenje drugih metoda plaćanja, dok je 59\% ispitanika zabrinuto za bezbednost. Trećina ispitanika ne poseduje telefone odgovarajućih karakteristika, dok 14\% potrošača ne razume različite opcije plaćanja.

Da bi neki sistem mobilnog plaćanja postao profitabilan za trgovce i servis porvajdere neophodno je da ga veliki broj korisnika prihvati. Mnogi trgovci smatraju da je široka baza korisnika neophodan preduslov da bi ponudili mogućnost mobilnog plaćanja. S druge strane, ukoliko velik broj trgovaca ne nudi ovu uslugu, ona ima manju vrednost za potencijalne korisnike. Iako mobilno plaćanje ima potencijal da poveća prodaju i smanji troškove, njegova prednost je umanjena nedostatkom odgovarajuće baze potrošača.

Trgovci i servis provajderi smatraju da je mobilno plaćanje posebno pogodno za naručivanje digitalnih sadržaja i usluga koje se mogu direktno poslati na mobilni telefon, kao što su karte za pozorište, koncerte, bioskope i slično, sadržaja kao što su igrice, muzika, novosti i razne usluge. Mnogi trgovci smatraju da je mobilno plaćanje nekompatibilno sa njihovim proizvodima i drugim metodama plaćanja koje nude. Takođe, nedostatak standarda predstavlja jednu od najvažnijih prepreka za prihvatanje mobilnog plaćanja od strane kupaca i trgovaca. Mnogo različitih solucija može da zbuni potrošače, pri čemu je za trgovce veoma skupo da ponude različite standarde plaćanja svojim kupcima. Zbog toga je poželjna kooperacija između različitih provajdera plaćanja, uz nametanje jednog glavnog standarda koji ima najveću verovatnoću da doživi uspeh.

Istraživanja, takođe pokazuju da korisnici smatraju da je mobilno plaćanje suviše kompleksno i komplikovano za korišćenje. Idealna solucija za korisnike podrazumevala bi malo kucanja i samo nekoliko koraka u procesu plaćanja. Brzina se smatra veoma bitnim faktorom za prihvatanje mobilnog plaćanja. Sa stanovišta trgovaca i servis provajdera, nova solucija plaćanja treba jednostavno da se integriše u postojeće sisteme i da omogući jednostavnu obradu transakcija. 
Sledeća barijera za prihvatanje mobilnog plaćanja od strane trgovaca su visoki troškovi, s obzirom na to da trgovci ne očekuju smanjenje troškova za svoju kompaniju od uvođenja ovog novog sistema plaćanja i smatraju da je njegova profitabilnost nesigurna. Nasuprot tome, iako je problem bezbednosti važan preduslov za prihvatanje mobilnog plaćanja, za većinu trgovaca on ne predstavlja značajnu barijeru za njegovo prihvatanje. Većina trgovaca očekuje da će u skorijoj budućnosti prihvatiti ovaj novi sistem plaćanja, koji se ne posmatra kao zamena za postojeće metode plaćanja, već kao komplementarna metoda uz već postojeće. Veliki potencijal za razvoj mobilnog bankarstva postoji u razvijenim azijskim državama koje su postepeno uvodile mobilno plaćanje i servise mobilnog bankarstva u čemu je najagresivnija bila Koreja (Tiwari \& Buse, 2007).

\section{REZIME}

Mobilno bankarstvo predstavlja šansu za banke da zadrže svoje klijente ponudom inovativnih servisa, kao i mogućnost da privuku nove klijente. Ono ima potencijal da postane jedna od najšire rasprostranjenih i prihvaćenih aplikacija u oblasti mobilne trgovine.

U radu su opisani razlozi koji utiču na prihvatanje servisa mobilnog bankarstva: neverovatan razvoj telekomunikacionog sektora, sve šira prisutnost mobilnih telefona i proces globalizacije koji kao posledicu ima veću mobilnost, što je uslovilo veću potrebu za mobilnim servisima koji se mogu realizovati u bilo koje vreme i na bilo kom mestu. S druge strane, objašnjene su osnovne prepreke za njihovo prihvatanje, kao što su otpor velikog dela stanovništva prema novim tehnologijama, i strah zbog nedovoljne bezbednosti ovakvih tehnologija.

\section{LITERATURA}

Anderson, J., Zavradinos, G., Reitsma, R., \& Jaddou, S. (2011). Global Mobile And Online Bankers. Preuzeto 03. 07. 2012. sa: http://www.forrester.com/Global+Mobile+And+Online +Bankers/fulltext/-/E-RES60105
Board of Governors of the Federal Reserve System. (2013). Consumers and Mobile Financial Services 2013, Preuzeto 01. 08. 2014. sa: http://www.federalreserve.gov/econresdata/consumers-and-mobile-financial-services-report-201303.pdf

Board of Governors of the Federal Reserve System. (2014). Consumers and Mobile Financial Services 2014, preuzeto 08. 02. 2015. sa: http://www.federalreserve.gov/econresdata/ consumers-and-mobile-financial-services-report-201403. pdf

Board of Governors of the Federal Reserve System. (2014). Consumers and Mobile Financial Services 2015, preuzeto 10.03.2015. sa: http://www.federalreserve.gov/econresdata/ consumers-and-mobile-financial-services-report-201503. pdf

Kam, B., \& Riquelme, H. (2007). An exploratory study of length andfrequency of Internet banking usage. Journal of Theoretical and AppliedElectronic Commerce Research, 2, 76-85.

Koenig-Lewis, N., Palmer, A., \& Moll, A. (2010). Predicting young consumers' take up of mobile banking services. International Journal of Bank Marketing, 28(5), 410-432

Lin, H. (2011). An empirical investigation of mobile banking adoption: The effect of innovation attributes and knowledge-based trust International. Journal of Information $\mathrm{Ma}$ nagement, 31(3), 252-260

Park, J., Snell, W., Ha, S., \& Chung, T-L. (2011). Consumer's post-adoption of $\mathrm{m}$-services: interest in future $\mathrm{m}$-services based on consumer evaluations of current m-services. Journal of Electronic Commerce Research, 12(3), 165-175.

Tiwari, R., \& Buse, S. (2007). The Mobile Commerce Prospects: A Strategic Analysis of Opportunities in the Banking Sector, Hamburg University Press

Tiwari, R., Buse, S., \& Herstatt, C. (2007). Mobile Services in Banking Sector: The Role of Innovative Business Solutions in Generating Competitive Advantage, Proceedings of the International Research Conference on Quality, Innovation and Knowledge Management, New Delhi

Uroš, T. (2014). Elektronsko bankarstvo. Beograd: Beogradska poslovna škola. 